\title{
Updates and Insights in the Diagnosis and Management of DRESS Syndrome
}

\author{
Elisa Maria Schunkert ${ }^{1} @ \cdot$ Sherrie Jill Divito ${ }^{1}$ \\ Accepted: 26 September 2021 / Published online: 9 November 2021 \\ (c) The Author(s), under exclusive licence to Springer Science+Business Media, LLC, part of Springer Nature 2021
}

\begin{abstract}
Purpose of Review To provide updates on recent advances in the diagnosis and management of drug reaction with eosinophilia and systemic symptoms (DRESS) syndrome.

Recent Findings The number of identified HLA allele associations with DRESS continues to grow. There is increasing evidence indicating viral infection, reactivation, and cross-reactivity may play key roles in disease. Translational work illuminated JAK/STAT activation in recalcitrant disease. There is expanding recognition of rapid-onset DRESS resulting from specific drugs.

Summary DRESS is a severe form of adverse drug reaction with potential for significant morbidity and mortality. Recent research advances may improve clinical care. HLA screening can now be performed to prevent disease in susceptible patients and may help identify culprit drugs in the near future. Viral testing should be performed on every patient, and if positive, patients potentially treated with antiviral therapy. JAK inhibitors may be an effective treatment option for DRESS. Early onset of disease relative to drug exposure should not exclude the diagnosis of DRESS.
\end{abstract}

Keywords Drug reactions - SCARs - Delayed-type drug hypersensitivity reactions · Drug reaction with eosinophilia and systemic symptoms (DRESS) $\cdot$ Culprit drug $\cdot$ RegiSCAR

\section{Introduction}

Drug reaction with eosinophilia and systemic symptoms (DRESS) syndrome is a severe form of drug hypersensitivity reaction with significant morbidity and mortality, potential for long-term sequelae and limited treatment options [1]. Prevalence is estimated at 2.18 to 9.63 per $100,000[2,3]$ and the increasing use of targeted anticancer agents and immuno-

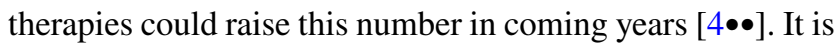
therefore critically important for dermatologists to be familiar with the diagnosis and management of DRESS, yet confusion exists in the field owing to several factors. These factors range from inconsistency in name and diagnostic criteria

This article is part of Topical Collection on Hospital-based Dermatology

Sherrie Jill Divito

sdivito@bwh.harvard.edu

1 Department of Dermatology, Brigham \& Women's Hospital, Harvard Medical School, 221 Longwood Ave, EBRC Rm 513, Boston, MA 02115, USA within and between specialties, to unclear understanding of how to translate recent scientific advancements to the clinic. This review aims to provide updates from the literature, highlight areas of confusion, contradiction, or requiring further investigation; and offer specific clinical examples and personal insights, with the goal of better equipping the physician in the diagnosis and management of DRESS.

\section{Clarification of Terminology}

Bocquet first introduced the acronym DRESS in 1996, at which time, it stood for drug rash with eosinophilia and systemic symptoms [5]. "Rash" was replaced with "reaction" because of the diverse range in cutaneous manifestations seen in DRESS syndrome, most notably, the absence of rash entirely, depending on which diagnostic criteria are used [5-7]. Whether cutaneous manifestations should be required to achieve a diagnosis of DRESS is a critical issue confounding research efforts and clinical care within and outside of dermatology. Drug-induced hypersensitivity reactions manifesting with many of the systemic signs and symptoms we associate with DRESS, without the rash, can and do occur. 
For example, hepatologists use the term drug-induced liver injury, or DILI, which encompasses both direct liver toxicity from drug and immune-mediated drug-induced liver injury [8]. Per the hepatology literature, immune-mediated DILI can occur with fever, rash, and eosinophilia (what we as dermatologists think of as DRESS) [8]. Similarly, druginduced acute interstitial nephritis classically manifests with rash, fever, and eosinophilia along with acute kidney injury starting days after initiation of drug, but can have a delayed development of weeks to months after drug initiation and present with signs/symptoms meeting diagnostic criteria of DRESS [9-11]. Author anecdote: we were consulted for question of DRESS in a patient with rash, fever, eosinophilia, and elevated liver function tests. The patient's rash was a contact dermatitis and unrelated to the systemic findings. The trainee communicated to the primary team that the patient does not have DRESS, which was interpreted to mean that none of the findings were related to drug, but in fact, the patient did have DILI (with a concurrent contact dermatitis), and needed to be managed as such.

The term drug-induced hypersensitivity syndrome (DIHS) is sometimes used alternatively or in addition to DRESS, and in the authors' opinion may be a better umbrella term, with drug rash with eosinophilia and systemic symptoms best viewed as a subset of DIHS with cutaneous involvement. Hypersensitivity syndrome (HSS), hypersensitivity syndrome named for the inciting drug (phenytoin hypersensitivity syndrome, allopurinol hypersensitivity syndrome, etc.), drug-induced delayed multiorgan hypersensitivity syndrome (DIDMOHS), and pseudolymphoma may also be seen in the literature.

\section{An Update on Pathogenesis with Specific Focus on Clinical Diagnosis and Management}

DRESS is a T cell-mediated delayed-type drug hypersensitivity reaction (DHR). Much remains unknown regarding pathogenesis; however, there have been major advances over recent years with potential for direct bearing on clinical care. First, there has been an explosion in the field of pharmacogenomics with the recognition that specific HLA alleles predispose to DRESS and other forms of delayedtype DHRs from certain drugs (Table 1). The prime example is the association between HLA*B57:01 and the antiretroviral agent abacavir $[12,13 \bullet]$. The PREDICT-1 study demonstrated HLA-B $* 57: 01$ carriage rates of $\sim 6 \%$ in Caucasians and $2-3 \%$ in African-Americans and admixed American populations, and that screening had a $47.9 \%$ positive predictive value, $100 \%$ negative predictive value, and completely eliminated abacavir-induced hypersensitivity [13•]. Given that HLA-B*57:01 screening fully prevents disease and is cost-effective, the US Food and Drug Administration recommends HLA screening of all patients prior to initiating abacavir therapy. Other known drug:HLA allele associations in DRESS are listed in Table 1. This list will continue to grow, as the search for at risk HLA alleles has become a major area of investigation. This is incredibly important clinically because for the first time, there is potential to prevent cases of DRESS by laboratory testing [14-16]. Moreover, the identification of specific drug:HLA allele associations has significant implications for identifying culprit drug. Instituting widespread HLA testing is not without complexity [17]. The major caveats for the clinician to recognize are that HLA allele associations are currently known for a limited number of drugs, there is a wide range in quality of data supporting HLA allele associations, prevalence of at risk HLA alleles can vary greatly amongst different populations so may not be applicable to the provider's patient/ population, and the positive and negative predictive values (PPV and NPV) of having predisposing HLA alleles are highly variable.

To this last point, abacavir:HLA-B*57:01 has the highest known PPV to our knowledge yet is only $~ 50 \%$ [13•]. The low positive predictive value of HLA allele associations suggests that additional factors contribute to onset of disease. One potential contributing factor is elevated drug level. In support, research has demonstrated increased risk

Table 1 HLA alleles associated with DRESS

\begin{tabular}{lllll}
\hline HLA allele & Culprit drug & Ethnic population & PPV/NPV & Reference \\
\hline HLA-B*57:01 & Abacavir & African, European, North American & $47.9 \% / 100 \%$ & {$[13 \bullet, 72,73]$} \\
HLA-B*58:01 & Allopurinol & European, Han Chinese, Korean, Taiwanese, Thai & $8.26 \% / 100 \%($ Thai) & {$[14,18,74-76]$} \\
HLA-A*31:01 & Carbamazepine & European, Han Chinese, Japanese, Tunesian & $0.77 \% / 99.98 \%($ European) & {$[77-80]$} \\
& & & $0.67 \% / 99.97 \%($ Chinese $)$ & $15.74 \% / 99.54 \%($ Thai) \\
HLA-B*13:01 & Dapsone & Chinese, Taiwanese, Thai & $--/--$ & {$[81-84]$} \\
$H L A-B * 51: 01$ & Phenytoin & Thai & $--/--$ & {$[85]$} \\
$H L A-C * 14: 02$ & Phenytoin & Thai & $--/--$ & {$[85]$} \\
HLA-B*53:01 & Raltegravir & African, Hispanic & $--/--$ & {$[86]$} \\
HLA-A*32:01 & Vancomycin & European & {$[87]$} \\
\hline
\end{tabular}

$H L A$, human leukocyte antigen; $P P V$, positive predictive value; $N P V$, negative predictive value 
of allopurinol-induced DRESS in HLA-B*58:01-positive patients with reduced kidney function $[18,19]$. Similarly, polymorphisms in genes encoding drug metabolizing enzymes or drug-drug interactions affecting liver metabolism resulting in elevated drug levels may contribute to disease [20-23]. These observations support considering liver and kidney function prior to/at the time of DRESS onset and potential drug-drug interactions when evaluating DRESS patients and attempting to identify culprit drug.

A second potential contributing factor is the role of viral infection or reactivation in DRESS. There are numerous publications demonstrating Human Herpesvirus-6 (HHV6), as well as HHV7, Epstein-Barr virus (EBV), and Cytomegalovirus (CMV) reactivation, or even sequential reactivation of several of these herpes family viruses in DRESS, though the incidence of virus reactivation is

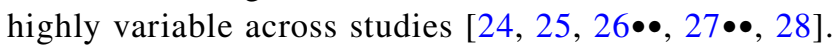
This latter point is obfuscated by the variable degree of testing performed. Moreover, it remains unclear whether (i) viral infection/reactivation triggers DRESS-like disease, or VRESS, viral reactivation eosinophilia and systemic symptoms [29] and the patient is in fact not reacting to drug; (ii) whether the combination of viral infection/ reactivation plus drug triggers DRESS; or (iii) viral reactivation occurs as a result of DRESS and potentially worsens disease. The clinical implications are twofold. First, if virally induced, the patient could safely continue his/ her medications and/or receive those medications in the future. Second, if DRESS-induced viral reactivation propagates disease, antiviral treatment should be considered. Notably, similar questions arise in the setting of SARSCoV2 infection and present a new diagnostic dilemma for dermatologists. Currently, reports of DRESS in COVID19 patients are limited and largely anecdotal [30,31], but this is an area of active investigation and may clarify the DRESS vs VRESS issue.

In a related arena, there has been increasing interest in the possibility that drug-reactive, DRESS-inducing $\mathrm{T}$ cells are actually virus-specific memory $\mathrm{T}$ cells that cross-react to drug [25]. This means that memory $\mathrm{T}$ cells were previously generated in response to viral infection, but HLA:drug looks the same to these memory T cells as HLA:virus and so the memory $\mathrm{T}$ cells mistakenly react to the drug. In support, HIV-specific T-cell clones cross-reacted in vitro with HLA$\mathrm{B} * 57: 01-$ positive cells in the presence of abacavir [32•], and Lucas et al. demonstrated drug-reactive naïve and memory $\mathrm{T}$ cells from blood of drug-naïve subjects [33]. The hallmark of a memory $\mathrm{T}$ cell response is that it occurs faster and more robustly than a primary $\mathrm{T}$ cell response. Cross-reactivity of pre-existing memory $\mathrm{T}$ cells generated as a result of prior viral infection could therefore potentially account for why some patients develop reactions more quickly despite first exposure to drug.
Finally, Kim et al. recently published a beautiful translational case study using single cell RNA sequencing to interrogate the aberrant immune response in a patient with recalcitrant DRESS [34••]. Results revealed activated Janus kinase-signal transducer and activator of transcription (JAKSTAT) pathway. Armed with this data, the clinicians successfully treated the patient with tofacitinib, a JAK inhibitor [34••]. Their findings illuminate not only immunopathogenesis but also a potential novel avenue of treatment for this severe disease.

\section{Diagnosis of DRESS Syndrome}

\section{Clinical Presentation During the Acute Phase of Disease}

DRESS is a systemic process classically characterized by cutaneous eruption, fever, lymphadenopathy, hematologic abnormalities, and visceral involvement [5]. Skin involvement is the most frequent finding in DRESS occurring in 99-100\% of patients, including both adults and children $[26 \bullet \bullet, 27 \bullet \bullet]$, with the caveat noted above regarding cutaneous involvement as a requirement for diagnosis. Rash most commonly presents as a symmetrical maculopapular (morbilliform) eruption including the trunk and extremities,

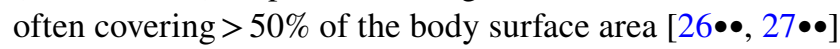
(Fig. 1a). The rash may have a deeper, more violaceous or plum hue than standard morbilliform eruption. Symptomatically, patients may experience pruritus or burning

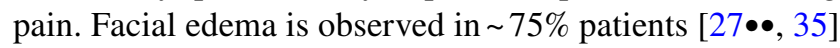
(Fig. 1b). Anecdotally, facial and ear rash with edema may signal that a drug-induced morbilliform eruption is progressing to, or at risk for progression to DRESS. Notably, rashes in DRESS can be quite polymorphic, and urticaria, pustules, blisters, exfoliative dermatitis, and target-lesions have been

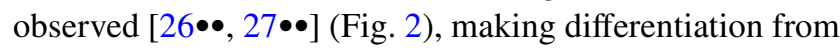
other severe cutaneous adverse reactions potentially difficult. Moreover, mucosal involvement can occur in DRESS, though is more mild than that seen in Stevens-Johnson Syndrome/toxic epidermal necrolysis or erythema multiforme [27••] (Fig. 2).

Signs and symptoms of systemic inflammation are evident though may precede, occur concurrently with, or lag behind cutaneous manifestations Patients may feel unwell with malaise. Objectively, fever $\geq 38.5^{\circ} \mathrm{C}$ is the most common sign of disease occurring in $\geq 90 \%$ of patients, and

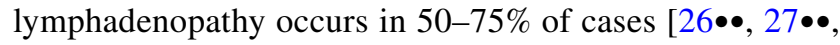
35]. Hematologic derangement is typically observed, with eosinophilia occurring in $\geq 90 \%$ (it is not universally present despite the "E" in DRESS) and atypical lymphocytosis in $\sim 65-80 \%$ of patients $[27 \bullet \bullet, 35]$. Additional abnormalities on complete blood count such as leukocytosis, neutrophilia, 
a

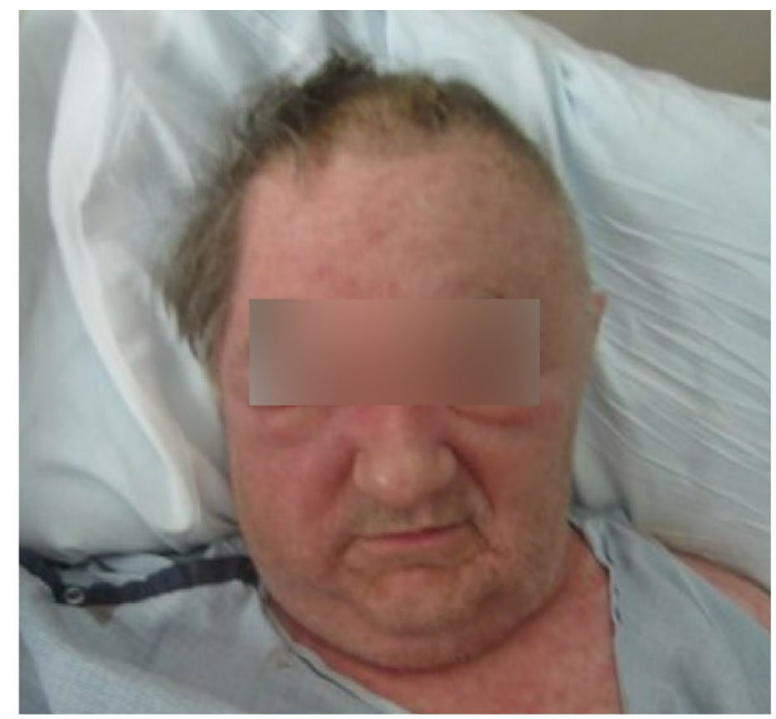

b

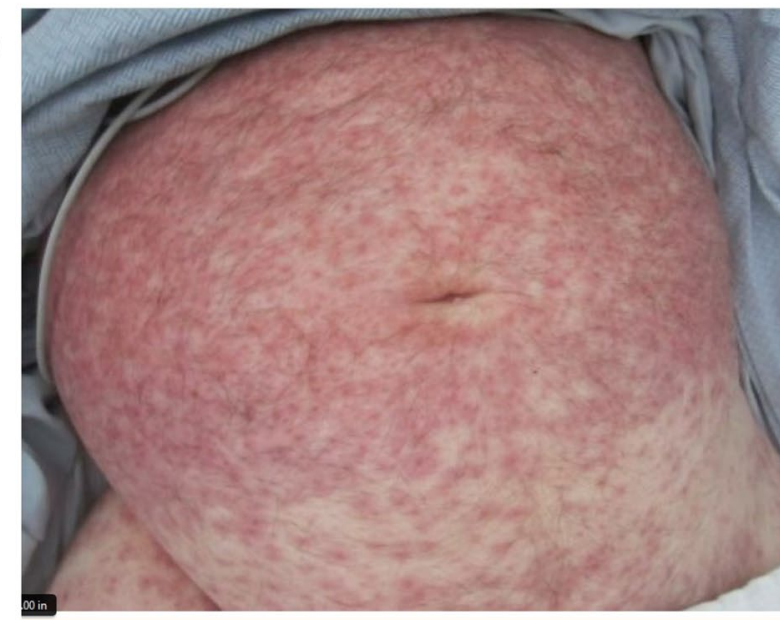

Fig. 1 Classic cutaneous findings in a patient with DRESS. a Morbilliform exanthem most prominent on the trunk. b Significant facial edema and erythema

lymphocytosis, and monocytosis can be observed in more than half of patients $[27 \bullet \bullet]$.

The most concerning feature of DRESS syndrome is involvement of 1 or more internal organs. The liver is the most commonly involved, with hepatitis occurring in $\geq 50 \%$

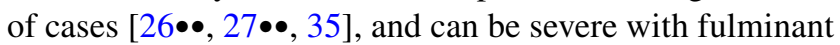
liver failure. Interstitial kidney and lung disease can also

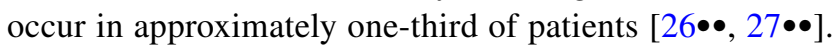
Cardiac involvement is an increasingly recognized manifestation in DRESS with potentially dangerous consequences including acute necrotizing eosinophilic myocarditis, cardiac

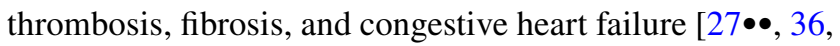
37]. Other organs can be affected during the acute phase of disease though less commonly so, including but not limited to the spleen, pancreas, stomach, and nervous system [26••, $27 \bullet \bullet, 38,39,40 \bullet \bullet]$.
Specific drugs appear to impart differential risk of particular internal organ involvement in DRESS. For example, sulfasalazine is associated with severe acute hepatitis, allopurinol with kidney injury, minocycline with lung involvement, and ampicillin and minocycline with DRESSassociated myocarditis [23, 41].

\section{Temporality of Disease Onset and Resolution}

Classic descriptions of DRESS highlight both the delayed onset of disease after initiation of culprit drug and slow resolution of disease with propensity to relapse and recur compared to other forms of delayed-type DHR. Onset is commonly quoted as 3-8 weeks after initiation of culprit drug, and the Japanese Severe Cutaneous Adverse Reaction (J-SCAR) scoring system requires the rash to develop $>3$ weeks after initiation of drug to qualify as DIHS/DRESS [6]. However, in 2019, Soria et al. published a retrospective study of rapid-onset DRESS, which occurs $\leq 15$ days after initial drug intake [42]. Drugs linked to rapid-onset DRESS included primarily antibiotics and iodinated contrast media. Rapid-onset DRESS as described by Soria et al. less frequently had lymphadenopathy in a retrospective comparison to standard onset DRESS, but otherwise is similar in presentation, including incidence of viral replication [42]. Interestingly, rapid-onset DRESS may reflect cases of prior sensitization to culprit drug, though data on prior exposure was not available in this study. Author opinion: though delayed onset of disease after drug initiation points toward DRESS, we advocate against dismissing DRESS (or a potential culprit drug) based on a shorter latency period between drug exposure and onset of disease.

\section{Laboratory, Pathology, and Radiologic Studies}

In any patient in whom a diagnosis of DRESS is being considered, several laboratory tests should be obtained and trended closely including complete blood count with differential and peripheral blood smear evaluating for eosinophilia, the presence of atypical lymphocytes and other hematologic abnormalities, liver function tests, and basic metabolic panel. Importantly, visceral involvement and laboratory abnormalities may lag behind cutaneous manifestations, and so in the authors opinion, follow-up bloodwork should be obtained even if laboratory tests are within normal limits on initial testing in any patient presenting with robust eruption, in particular if prominent facial/ear involvement, the patient is feeling systemically unwell, or has fever or lymphadenopathy. Additional laboratory testing should be driven by signs/symptoms of internal organ involvement, for example, troponins, Creatine kinase-MB, and NT-proBNP if cardiac involvement is suspected, or amylase and lipase if pancreatic involvement is suspected. Urinalysis and urine 
a

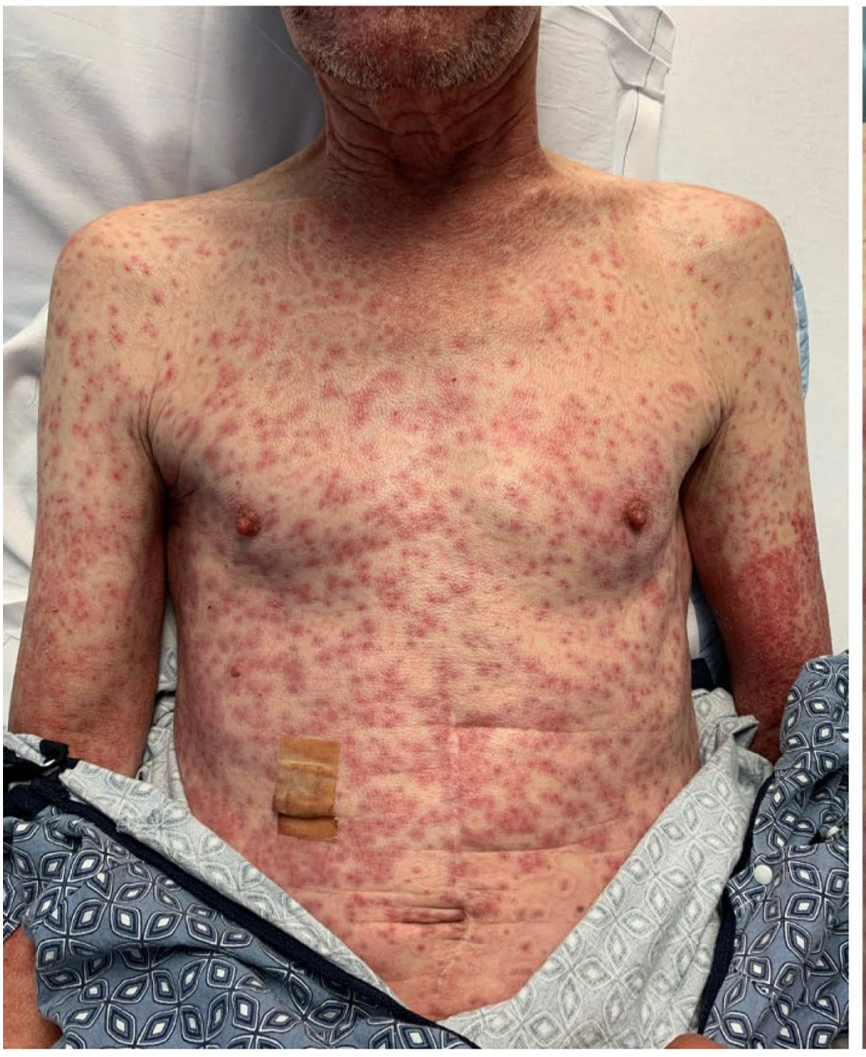

c

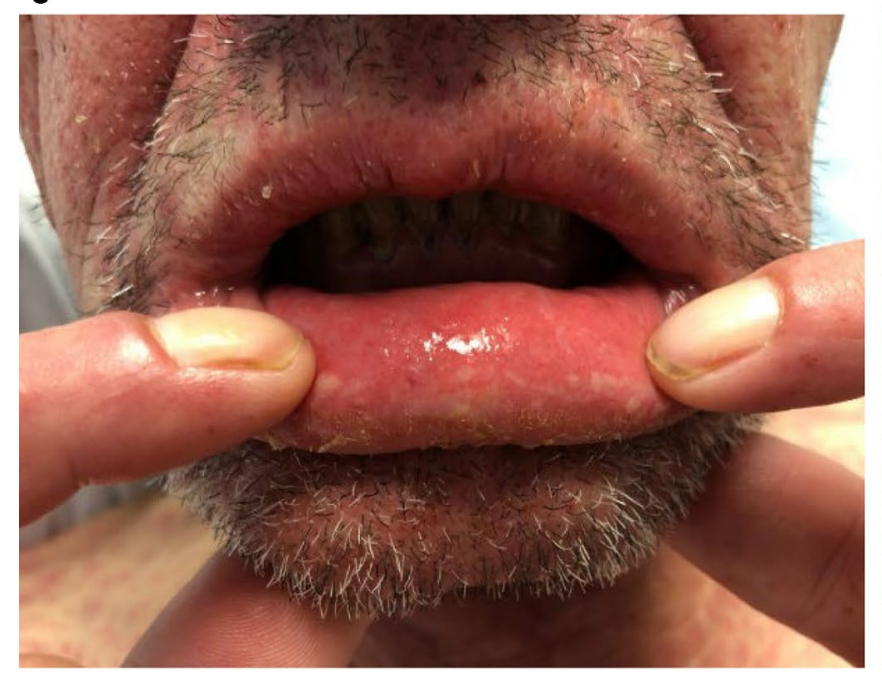

b

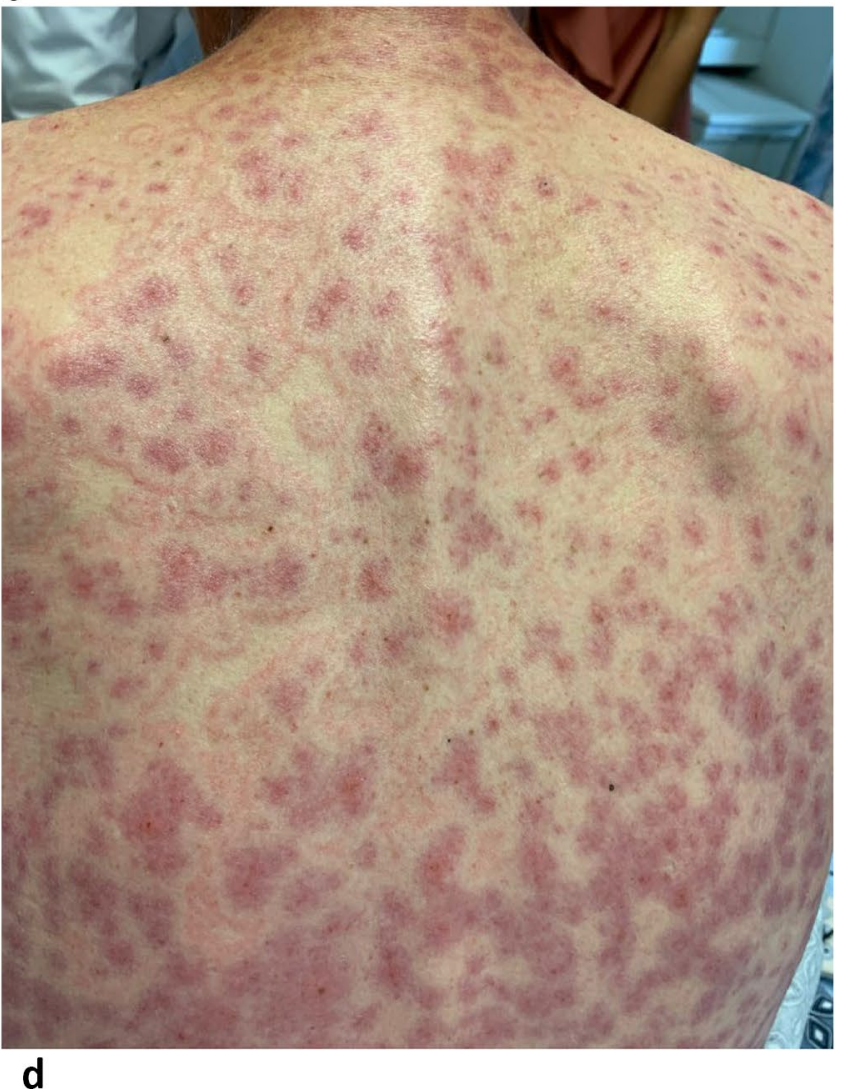

d

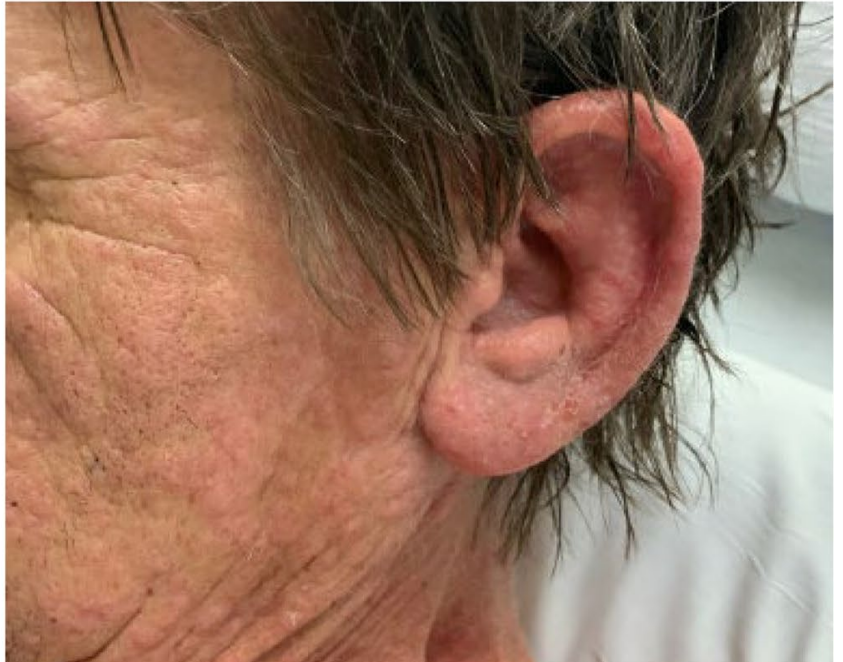

Fig. 2 Atypical cutaneous presentation of DRESS. Target and target-like macules and papules on the a chest and abdomen and b back. $\mathbf{c}$ Mild mucosal involvement yet with $\mathbf{d}$ prominent ear involvement classically seen in DRESS

sedimentation may be considered if abnormal renal function, though may be unreliable in the diagnosis of drug-induced acute interstitial nephritis [11]. Current data and recommendations on viral testing (by PCR or serologies) and interpretation of results are variable [43-45]. Given potential for viral infection/reactivation to cause or exacerbate DRESS, the authors currently advise testing HHV6, HHV7, CMV, and EBV viral loads via PCR from peripheral blood at the time of diagnosis/initial work-up, and if negative, perform repeat testing if the patient's disease is recalcitrant to systemic immunosuppressive treatment (for consideration of antiviral therapy). Finally, additional laboratory tests may be considered to rule out alternative diagnoses (for example, but not limited to, antinuclear antibody; blood culture; hepatitis A, B, and C viral studies; chlamydia; and mycoplasma [7]).

Histologic findings are variable on skin biopsy in DRESS and none is pathognomonic. Studies have reported 
dyskeratosis in $53-97 \%$, spongiosis in 40-78\%, and interface vacuolarization in $74-91 \%$ of DRESS cases [35, 46, 47]. Lymphocytic infiltrate ranging from perivascular to dense is observed, and eosinophils are variably present (anywhere from 20 to $80 \%$ of cases have been reported) [35, 46, 47]. Comparison to morbilliform drug eruption revealed more robust inflammatory infiltrate and greater degree of dyskeratosis in DRESS in two studies [46, 48], though a subset of DRESS cases can have a limited infiltrate similar to morbilliform drug eruption [47]. Finally, though the presence of atypical lymphocytes on histology has been suggested as a potential feature of DRESS, atypical lymphocytes were observed in a retrospective study in approximately one-third of cases of both DRESS and morbilliform drug eruption [47]. Given the variability in histologic findings, the authors do not recommend performing skin biopsy to distinguish morbilliform drug eruption from DRESS. Rather, the utility of skin biopsy in potential DRESS cases lies in ruling out alternative diagnoses, though even here diagnosis can be challenging, as histologic findings in DRESS can mimic those of erythema multiforme, AGEP [47], and even angioimmunoblastic T-cell lymphoma [49].

Additional diagnostic testing is typically driven by history and physical exam, for example, pulmonary function testing and high-resolution computed tomography of the chest may be indicated if drug-induced lung injury is suspected. A possible exception may be cardiac evaluation. The most common signs and symptoms of cardiac involvement in DRESS patients are dyspnea, tachycardia, hypotension, and chest pain; however, patients may be initially asymptomatic [36]. Given the potential for significant morbidity and rapid mortality, some experts advise cardiac screening including ECG and echocardiogram in any patient with diagnosis of DRESS [36].

\section{Diagnostic Scoring Systems}

Given the clinical complexity, heterogeneity in presentation, and overlapping features with other diseases, multiple scoring systems and guidelines have been suggested over the past $25+$ years to facilitate diagnosis of DRESS. A review by A.R. Cardones from 2020 nicely compares the three major scoring systemics [50] which include Bocquet's, published in 1996 [5], the J-SCAR criteria from 2006 [6], and the European RegiSCAR criteria from 2007 [7]. The RegiSCAR criteria are outlined in Table 2 as it is the most detailed, and potentially the most frequently used, particularly for research/publication purposes. The recently published Spanish guidelines for DRESS advise the use of RegiSCAR criteria in clinical diagnosis [40••], while Kim et al. conducted a comparative retrospective analysis between the three criteria and concluded that while the RegiSCAR criteria are the most accurate, the Bocquet's criteria were the easiest to apply and most suitable for the clinical setting [51]. The J-SCAR criteria were potentially too limiting, missing cases of DRESS identified by the RegiSCAR and Bocquet's criteria [51]. Practically speaking, the Cardones review mentions unpublished data suggesting that many clinicians do not rely on these scoring systems in their diagnosis of DRESS [50], which has been the authors' experience as well.

We, the authors, encourage trainees to use the RegiSCAR criteria as an aid in the diagnosis of DRESS and as a learning tool. It serves as an excellent reminder of the breadth of potential organ involvement, it provides specific laboratory values necessary for inclusion (in our experience, this is very helpful as there is a tendency for clinicians to incorrectly diagnose systemic involvement with even minor laboratory aberrancies), and it cues exclusion of other possible etiologies. To this last point, though the RegiSCAR criteria specify lupus/connective tissue disease (with ANA testing) and particular infections (with blood cultures; hepatitis A, B, and $\mathrm{C}$; chlamydia; and mycoplasma testing), other etiologies must be considered and excluded on a case-by-case basis, which may not be obvious if one is simply working through the scoring algorithm. Author anecdote: we were consulted for question drug reaction on a patient with hematologic malignancy. The patient had a spongiotic dermatitis, fever, lymphadenopathy, eosinophilia, and drug exposure in the timeline consistent with DRESS. A trainee concluded that the patient had a probable case based on RegiSCAR criteria. However, the patient's rash was paraneoplastic, the fever and lymphadenopathy were secondary to infection and malignancy, respectively, and the eosinophilia difficult to interpret in the setting of the hematologic derangement. The other limitation of the RegiSCAR criteria is that delayed resolution $\geq 15$ days is a criterion, which is useful for retrospective research purposes but not applicable during initial disease when correct diagnosis is essential for clinical care. Lastly, the RegiSCAR criteria do not include viral reactivation, though, we, the authors, likewise do not include viral infection or reactivation as a criterion for determining diagnosis of DRESS at this time.

\section{“Mini-DRESS"}

A controversial topic regarding DRESS diagnosis is the view that DRESS exists on a spectrum in regard to severity. The terms "mini-DRESS" or "skirt syndrome" have been proposed [52] to refer to mild forms of DRESS. Others are of the opinion that mild DRESS does not exist and is in fact an oxymoron. The controversy in part stems from the heterogeneity in clinical manifestations between patients and variable timing of onset of manifestations even within one patient. Moreover, in cases of robust drug rash, particularly with prominent facial and ear involvement and/or early signs/symptoms of systemic inflammation (fever, malaise, etc.), many experts stop the offending 
Table 2 RegiSCAR criteria for DRESS and validation scoring system

\begin{tabular}{|c|c|c|c|c|c|c|}
\hline \multirow[t]{2}{*}{ Criteria $(1-7)^{*}$} & \multicolumn{6}{|c|}{ Score $* * *$} \\
\hline & -1 & 0 & +1 & +2 & Min.** & Max.** \\
\hline \multicolumn{7}{|l|}{ 1) Acute skin eruption } \\
\hline a) Skin rash extended ( $\%$ BSA) & & a) $\mathrm{No} / \mathrm{U}$ & a) $>50 \%$ BSA & & -2 & +2 \\
\hline b) Skin rash suggesting DRESS & b) No & b) $\mathrm{U}$ & b) Yes & & & \\
\hline c) Biopsy suggesting DRESS & c) No & c) $\mathrm{Yes} / \mathrm{U}$ & & & & \\
\hline 2) Fever $\geq 38.5 \mathrm{C}$ & $\mathrm{No} / \mathrm{U}$ & Yes & & & -1 & 0 \\
\hline 3) Lymphadenopathy & & $\mathrm{No} / \mathrm{U}$ & Yes & & 0 & +1 \\
\hline 4) Internal organ involvement & & & & & 0 & +2 \\
\hline a) Liver & & a) $\mathrm{No} / \mathrm{U}$ & a) Yes & & & \\
\hline b) Kidney & & b) $\mathrm{No} / \mathrm{U}$ & b) Yes & & & \\
\hline c) Lung & & c) $\mathrm{No} / \mathrm{U}$ & c) Yes & & & \\
\hline d) Muscle/heart & & d) $\mathrm{No} / \mathrm{U}$ & d) Yes & & & \\
\hline e) Pancreas & & e) $\mathrm{No} / \mathrm{U}$ & e) Yes & & & \\
\hline f) Other & & f) $\mathrm{No} / \mathrm{U}$ & f) Yes & & & \\
\hline 5) Eosinophilia & & & & & 0 & +2 \\
\hline a) Eosinophils & & & a) $0.7-1.49 \times 10^{9} \mathrm{~L}^{-1}$ & a) $\geq 1.5 \times 10^{9} \mathrm{~L}^{-1}$ & & \\
\hline b) Eosinophils, if leukocytes $<4.0 \times 10^{9} \mathrm{~L}^{-1}$ & & & b) $19.9 \%$ & b) $\geq 20 \%$ & & \\
\hline 6) Atypical lymphocytes & & $\mathrm{No} / \mathrm{U}$ & Yes & & 0 & +1 \\
\hline 7) Thrombocytopenia & -- & -- & -- & -- & & \\
\hline \multicolumn{7}{|l|}{ Also part of scoring system } \\
\hline Resolution time $>15$ days & $\mathrm{No} / \mathrm{U}$ & Yes & & & -1 & 0 \\
\hline Exclusion of the following: & & & Yes & & 0 & +1 \\
\hline -Antinuclear antibodies & & & & & & \\
\hline -Blood culture & & & & & & \\
\hline -Serology for hepatitis A, B, C & & & & & & \\
\hline -Chlamydia or mycoplasma & & & & & & \\
\hline
\end{tabular}

$U$, unknown; $B S A$, body surface area

* $\geq 3$ criteria + are required for diagnosis DRESS

** Minimum or maximum points scorable per criteria (e.g., even if in criteria (4) $3 \times$ organs are positive, only 2 points can be scored in that category)

${ }^{* * * *}$ Validation scoring system can be applied to identify if diagnosis is not the case (score: $\left.<2\right)$, possible (score: $2-3$ ), probable (score: 4-5), or definite (score: $>5$ )

Adapted from $[7,27 \bullet \bullet][50]$

drug and treat aggressively before visceral involvement begins or meets criteria for diagnosis in an effort to prevent DRESS. Patients may not meet diagnostic criteria in these cases though the natural course of their disease has been manipulated. Complicating matters further, morbilliform drug eruption can present variably in severity not only in cutaneous manifestations but also with low grade fever and eosinophilia. The authors' personal approach is to diagnose these types of cases as drug hypersensitivity reaction at risk for evolving to (or if re-exposed to culprit drug, recurring as) DRESS and treating systemically to prevent severe disease unless otherwise contraindicated.

\section{Overlap Syndromes}

A potential source of clinical complexity is so-called overlap cases, which refer to cases presenting with signs and symptoms of DRESS along with SJS/TEN or acute generalized exanthematous pustulosis (AGEP). A retrospective study by Bouvresse et al. showed that application of RegiSCAR criteria enabled resolution of $20 \%$ of cases initially suggestive of overlap, to $<3 \%$ as true overlap cases [53]. Notably though, diagnostic resolution was achievable only retrospectively; in the acute phase of disease, such distinction may not be possible.

\section{Management of DRESS}

\section{Identifying Culprit Drug}

The most important intervention in DRESS syndrome is the immediate discontinuation of culprit drug [54]. This necessitates correct culprit drug identification which can be quite challenging as many patients take multiple 
medications. There is currently no test during active disease that can reliably determine culprit drug, so the gold standard is physician identification based on patient history, coupled with recognizing "high-risk" medications. To achieve the latter, clinicians commonly rely on reports of high-risk drugs in the literature. DRESS is most commonly associated with anticonvulsants, antibiotics, antiviral drugs, allopurinol, and sulfonamides [23] (Table 3). Increasingly, targeted anti-cancer treatments and immune

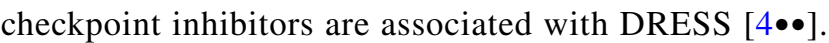
Imatinib, a BCR-ABL tyrosine kinase inhibitor used to treat several cancers, is currently the most common anticancer therapy to cause DRESS $[4 \bullet \bullet]$. The authors raise a note of caution, as the data on high-risk medications may require re-evaluation given the growing insights regarding rapid-onset DRESS and the potential for VRESS misdiagnosed as DRESS. Moreover, though halting culprit drug is paramount in clinical care, discontinuing or labeling a patient allergic to a drug that in fact the patient could safely take is not without consequences. The replacement medication could be less effective, more dangerous, and/ or more expensive. Going forward, it may be possible to incorporate HLA testing during active disease to help rule in/out potential culprit drugs, though further research is required on this topic.

Several in vivo and in vitro tests have been proposed to establish drug causality after disease resolution. The lymphocyte transformation test (LTT) exposes a patient's peripheral blood $\mathrm{T}$ cells to drug in vitro then uses various assays and markers to interrogate $\mathrm{T}$ cell response. Historically, though the test could demonstrate sufficient specificity in some cases, sensitivity was typically too low for clinical utility [55]. Furthermore, protocols were not standardized or scaled for broader application [56]. In 2018, Cabañas et al. published a study of 41 patients demonstrating LTT sensitivity of $73 \%$ and specificity $82 \%$ across DRESS cases during the recovery phase of disease, with testing particularly good for anticonvulsants and antituberculosis medications [57•]. Moreover, they provided an optimized analysis to improve and standardize results [57•]. In vivo skin testing has also been attempted, by patch testing and/or intradermal testing. Results are highly variable depending on the drug being tested and timing of testing relative to disease onset and resolution, though for some drugs, skin testing may be a useful testing option $[13 \bullet, 56,58,59]$. Drug challenges are generally contraindicated in patients with DRESS as it could potentially lead to lethal recurrence of disease. However, if there is no effective alternative treatment available, a drug could potentially be re-introduced in a hospital setting that allows for prompt identification of recurrence and intervention with systemic immunosuppression in case of a reaction [60]. Patients should be
Table 3 Culprit drugs associated with DRESS

\begin{tabular}{|c|c|}
\hline Drug category & Drugs \\
\hline Antibacterial & $\begin{array}{l}\text { Amoxicillin } \\
\text { Ampicillin } \\
\text { Dapsone } \\
\text { Ethambutol } \\
\text { Isoniazid } \\
\text { Levofloxacin } \\
\text { Minocycline } \\
\text { Piperacillin/tazobactam } \\
\text { Pyrazinamide } \\
\text { Rifampin } \\
\text { Streptomycin } \\
\text { Sulfamethoxazole-trimethoprim } \\
\text { Vancomycin }\end{array}$ \\
\hline Antiarrhythmic & Mexiletine \\
\hline Antiviral & $\begin{array}{l}\text { Abacavir } \\
\text { Boceprevir } \\
\text { Nevirapine } \\
\text { Telaprevir }\end{array}$ \\
\hline Analgesic/anti-inflammatory & $\begin{array}{l}\text { Celecoxib } \\
\text { Diclofenac } \\
\text { Ibuprofen } \\
\text { Sulfasalazine }\end{array}$ \\
\hline Anticonvulsants & $\begin{array}{l}\text { Carbamazepine } \\
\text { Lamotrigine } \\
\text { Oxcarbazepine } \\
\text { Phenobarbital } \\
\text { Phenytoin }\end{array}$ \\
\hline Antidepressants & Amitriptyline \\
\hline Gastric acid inhibitors & $\begin{array}{l}\text { Omeprazole } \\
\text { Strontium ranelate }\end{array}$ \\
\hline Immunotherapeutics & Hydroxychloroquine \\
\hline Targeted anticancer therapies & $\begin{array}{l}\text { Daclizumab } \\
\text { Imatinib } \\
\text { Sorafenib } \\
\text { Vemurafenib }\end{array}$ \\
\hline Uric acid regulators & Allopurinol \\
\hline
\end{tabular}

*Excludes drugs limited to only one case report unless culprit drug was identified by follow-up testing

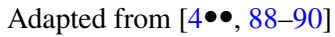

educated on meticulous avoidance of the offending drug and cross-reacting drugs. The Spanish guidelines include a concise summary of known cross-reactivity for common culprit drugs in DRESS that can serve as a useful clinical resource $[40 \bullet \bullet]$.

\section{Treatment}

A multidisciplinary team composed of the appropriate specialists depending on organs involved is recommended. If severe organ disease, intensive care may be necessary. Notably, we do recommend care at a hospital with dermatologists and other specialists familiar with this disease to ensure correct diagnosis, monitoring, and treatment. Systemic corticosteroids are currently the treatment of choice for DRESS [61], 
though there is no agreed upon dosing algorithm. While some experts advocate for 40 to $60 \mathrm{mg}$ oral prednisolone daily during active disease, others are more aggressive. We generally treat DRESS with i.v. methylprednisolone at $1 \mathrm{mg} /$ $\mathrm{kg}$ (potentially even $1.5 \mathrm{mg} / \mathrm{kg}$ ) depending on disease severity and comorbidities. We preferentially prescribe methylprednisolone in DRESS patients since prednisone requires liver metabolism into active form, and i.v. over p.o. route of administration to bypass potential for decreased absorption in hospitalized patients. To our knowledge, there is only one published prospective study of corticosteroids in DRESS. Natkunarajah et al. treated 10 patients with pulse i.v. methylprednisolone for 3 consecutive days $(500 \mathrm{mg} / \mathrm{day}<90 \mathrm{~kg}$; $1000 \mathrm{mg} /$ day $>90 \mathrm{~kg}$ ) followed by $30 \mathrm{mg}$ prednisolone p.o., tapered by $10 \mathrm{mg}$ every 10 days [62]. They observed rapid resolution in patient's manifestations though one patient still experienced fulminant liver failure requiring transplantation. Experts generally agree that a slow taper over weeks to months once clinical and laboratory abnormalities stabilize is advisable given the propensity for DRESS to relapse $[54,61]$.

Reportedly, many cases of DRESS are treated with topical corticosteroids alone. A retrospective study of 38 patients demonstrated that topical treatment $(n=25)$ was sufficient for treatment of more mild disease, though one patient died [63]. These cases met the definition of "probable" DRESS by RegiSCAR criteria though degree of organ involvement was not detailed so whether this cohort included "mini-DRESS" cases is unclear. Patients treated with topicals alone had reduced infectious complications compared to those treated with systemic steroids, though the systemic steroid group had more severe disease to begin with so causality cannot be concluded. Importantly, systemic corticosteroids significantly reduce the risk of death from DRESS-associated myocarditis [64] and interestingly, high-dose systemic corticosteroids initiated early in disease are associated with reduced reactivation of HHV6 [65•].

Numerous alternative agents and avenues have been tried in cases where systemic corticosteroids were contraindicated or failed including cyclophosphamide, cyclosporine, interferons, mycophenolate mofetil, muromonab-CD3, rituximab, and plasmapheresis [50, 54]. A retrospective case-control study showed positive outcomes with cyclosporine in patients that could not receive glucocorticoids [66]. Cyclosporine may be beneficial in DRESS given its rapid onset of action as an inhibitor of $\mathrm{T}$ cell proliferation. Intravenous immunoglobulin, IVIG, has been used successfully per published reports, but the only prospective study of IVIG in DRESS was stopped secondary to safety concerns [67]. Recently, JAK inhibition has gained attention given translational research results and has demonstrated efficacy in two cases of

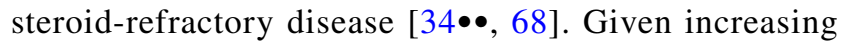
data intimating that viral reactivation exacerbates DRESS, treatment with antiviral agents, particularly ganciclovir, may also be considered.

\section{Long-term Sequelae of DRESS Syndrome}

According to a study by Chen et al. $>11 \%$ of DRESS patients are affected by chronic complications [69]. Longterm sequelae can be a continuation of organ dysfunction that developed during the acute phase of disease or appear after a symptom-free period, in some cases after many months. In younger patients, long-term sequelae tend to manifest as autoimmune disease (autoimmune thyroiditis, type 1 diabetes, alopecia, myocarditis, bullous pemphigoid, vitiligo, scleroderma, and systemic lupus erythematosus), while elderly patients may experience end-organ failure $[38,69,70]$. There are no agreed upon guidelines regarding frequency and duration of patient follow-up but long-term sequelae can begin up to 2 years after acute disease [23], so routine follow-up for at least that period is generally advisable. Patients might also suffer from depression, anxiety, and fear toward taking medications. Systematic screening for psychological symptoms during the first 12 months postdisease is recommended [71].

\section{Conclusion}

DRESS is severe form of drug hypersensitivity reaction marked by systemic inflammation affecting multiple organ systems. Clear consensus on diagnosis and terminology within and between specialties is lacking and contributes to clinical confusion and complicates research efforts. Further confounding clinical care is the lack of a test capable of reliably identifying culprit drug. Cause for optimism exists though as recent research advances have made significant inroads into multiple facets of disease ranging from basic science to epidemiology to treatment. With this increasingly solid framework in place, we anticipate continued progress in coming years in the diagnosis and management of DRESS.

Acknowledgements The authors would like to thank the Drs. William Lin and Nora Barrett for use of their photographs.

Funding This work was funded by the National Institutes of Health DP5 OD023091 and R21 AI15065 (SJD) and the German Research Foundation, DFG Project number: 423175926, GZ: SCHU 3377/1-1 (EMS).

\section{Compliance with Ethical Standards}

Conflict of Interest The authors have no conflicts of interest to declare. 
Human and Animal Rights and Informed Consent This article does not contain any studies with human or animal subjects performed by any of the authors.

\section{References}

Papers of particular interest, published recently, have been highlighted as:

- Of importance

$\bullet$ Of major importance

1. Chiou CC, Yang LC, Hung SI, Chang YC, Kuo TT, Ho HC, et al. Clinicopathological features and prognosis of drug rash with eosinophilia and systemic symptoms: a study of 30 cases in Taiwan. J Eur Acad Dermatol Venereol. 2008;22(9):1044-9. https://doi.org/10.1111/j.1468-3083.2008.02585.x.

2. Wolfson AR, Zhou L, Li Y, Phadke NA, Chow OA, Blumenthal KG. Drug reaction with eosinophilia and systemic symptoms (DRESS) syndrome identified in the electronic health record allergy module. J Allergy Clin Immunol Pract. 2019;7(2):63340. https://doi.org/10.1016/j.jaip.2018.08.013.

3. Hiransuthikul A, Rattananupong T, Klaewsongkram J, Rerknimitr P, Pongprutthipan M, Ruxrungtham K. Drug-induced hypersensitivity syndrome/drug reaction with eosinophilia and systemic symptoms (DIHS/DRESS): 11 years retrospective study in Thailand. Allergol Int. 2016;65(4):432-8. https://doi.org/10.1016/j. alit.2016.04.001.

4.•• Chen CB, Wu MY, Ng CY, Lu CW, Wu J, Kao PH, et al. Severe cutaneous adverse reactions induced by targeted anticancer therapies and immunotherapies. Cancer Manag Res. 2018;10:12591273. https://doi.org/10.2147/CMAR.S163391. Comprehensive review of severe delayed type cutaneous drug reactions due to targeted anticancer therapies and immunotherapies.

5. Bocquet H, Bagot M, Roujeau JC. Drug-induced pseudolymphoma and drug hypersensitivity syndrome (drug rash with eosinophilia and systemic symptoms: DRESS). Semin Cutan Med Surg. 1996;15(4):250-7. https://doi.org/10.1016/s10855629(96)80038-1.

6. Shiohara T, Inaoka M, Kano Y. Drug-induced hypersensitivity syndrome (DIHS): a reaction induced by a complex interplay among herpesviruses and antiviral and antidrug immune responses. Allergol Int. 2006;55(1):1-8. https://doi.org/10.2332/ allergolint.55.1.

7. Kardaun SH, Sidoroff A, Valeyrie-Allanore L, Halevy S, Davidovici BB, Mockenhaupt M, et al. Variability in the clinical pattern of cutaneous side-effects of drugs with systemic symptoms: does a DRESS syndrome really exist? $\mathrm{Br}$ J Dermatol. 2007;156(3):609-11. https://doi.org/10.1111/j. 1365-2133.2006.07704.x.

8. David S, Hamilton JP. Drug-induced liver injury. US Gastroenterol Hepatol Rev. 2010;6:73-80.

9. Qadri I, Zeng X, Guo R, Koratala A. Acute interstitial nephritis and DRESS syndrome without eosinophilia associated with cefepime. BMJ Case Rep. 2017;2017. https://doi.org/10.1136/ bcr-2017-221401.

10. Augusto JF, Sayegh J, Simon A, Croue A, Chennebault JM, Cousin M, et al. A case of sulphasalazine-induced DRESS syndrome with delayed acute interstitial nephritis. Nephrol Dial Transplant. 2009;24(9):2940-2. https://doi.org/10.1093/ndt/ gfp277.

11. Moledina DG, Perazella MA. Drug-induced acute interstitial nephritis. Clin J Am Soc Nephrol. 2017;12(12):2046-9. https:// doi.org/10.2215/CJN.07630717.
12. Mallal S, Nolan D, Witt C, Masel G, Martin AM, Moore C, et al. Association between presence of HLA-B*5701, HLA-DR7, and HLA-DQ3 and hypersensitivity to HIV-1 reverse-transcriptase inhibitor abacavir. Lancet. 2002;359(9308):727-32. https://doi. org/10.1016/s0140-6736(02)07873-x.

13. Mallal S, Phillips E, Carosi G, Molina JM, Workman C, Tomazic $\mathrm{J}$, et al. HLA-B*5701 screening for hypersensitivity to abacavir. N Engl J Med. 2008;358(6): 568-579. https://doi.org/10.1056/ NEJMoa0706135. Double-blind, prospective, randomized study to evaluate PPV and NPV of HLA-B $* 57: 01$ in patients planning to received abacavir. Showed that HLA-B*5701 screening significantly reduced the risk of hypersensitivity reaction to abacavir.

14. Ko TM, Tsai CY, Chen SY, Chen KS, Yu KH, Chu CS, et al. Use of HLA-B*58:01 genotyping to prevent allopurinol induced severe cutaneous adverse reactions in Taiwan: national prospective cohort study. BMJ. 2015;351: h4848. https://doi.org/10. 1136/bmj.h4848.

15. Ponzo MG, Miliszewski M, Kirchhof MG, Keown PA, Dutz JP. HLA-B*58:01 genotyping to prevent cases of DRESS and SJS/TEN in East Asians treated with allopurinol-a Canadian missed opportunity [Formula: see text]. J Cutan Med Surg. 2019;23(6):595-601. https://doi.org/10.1177/1203475419867599.

16. Liu H, Wang Z, Bao F, Wang C, Sun L, Zhang H, et al. Evaluation of prospective HLA-B*13:01 screening to prevent dapsone hypersensitivity syndrome in patients with leprosy. JAMA Dermatol. 2019;155(6):666-72. https://doi.org/10.1001/jamadermatol.2018. 5360.

17. Divito SJ. Implementation of genetic screening to prevent severe cutaneous adverse drug reactions is crucial-rebuttal from the devil's antagonist-reply. JAMA Dermatol. 2020;156(2):221-2. https://doi.org/10.1001/jamadermatol.2019.3335.

18. Ng CY, Yeh YT, Wang CW, Hung SI, Yang CH, Chang YC, et al. Impact of the HLA-B $(*) 58: 01$ allele and renal impairment on allopurinol-induced cutaneous adverse reactions. J Invest Dermatol. 2016;136(7):1373-81. https://doi.org/10.1016/j.jid. 2016.02.808.

19. Chung WH, Chang WC, Stocker SL, Juo CG, Graham GG, Lee $\mathrm{MH}$, et al. Insights into the poor prognosis of allopurinolinduced severe cutaneous adverse reactions: the impact of renal insufficiency, high plasma levels of oxypurinol and granulysin. Ann Rheum Dis. 2015;74(12):2157-64. https://doi.org/10.1136/ annrheumdis-2014-205577.

20. Sacco JC, Abouraya M, Motsinger-Reif A, Yale SH, McCarty CA, Trepanier LA. Evaluation of polymorphisms in the sulfonamide detoxification genes NAT2, CYB5A, and CYB5R3 in patients with sulfonamide hypersensitivity. Pharmacogenet Genomics. 2012;22(10):733-40. https://doi.org/10.1097/FPC. 0b013e328357a735.

21. Shear NH, Spielberg SP, Grant DM, Tang BK, Kalow W. Differences in metabolism of sulfonamides predisposing to idiosyncratic toxicity. Ann Intern Med. 1986;105(2):179-84. https://doi. org/10.7326/0003-4819-105-2-179.

22. Wolkenstein P, Charue D, Laurent P, Revuz J, Roujeau JC, Bagot M. Metabolic predisposition to cutaneous adverse drug reactions. Role in toxic epidermal necrolysis caused by sulfonamides and anticonvulsants. Arch Dermatol. 1995;131(5):544-51.

23. Husain Z, Reddy BY, Schwartz RA. DRESS syndrome: Part I. Clinical perspectives. J Am Acad Dermatol. 2013;68(5):693 e1-14; quiz 706-8. https://doi.org/10.1016/j.jaad.2013.01. 033.

24. Seishima M, Yamanaka S, Fujisawa T, Tohyama M, Hashimoto K. Reactivation of human herpesvirus (HHV) family members other than HHV-6 in drug-induced hypersensitivity syndrome. Br J Dermatol. 2006;155(2):344-9. https://doi.org/10.1111/j. 1365-2133.2006.07332.x. 
25. Pavlos R, White KD, Wanjalla C, Mallal SA, Phillips EJ. Severe delayed drug reactions: role of genetics and viral infections. Immunol Allergy Clin North Am. 2017;37(4):785-815. https:// doi.org/10.1016/j.iac.2017.07.007.

26.• Metterle L, Hatch L, Seminario-Vidal L. Pediatric drug reaction with eosinophilia and systemic symptoms: a systematic review of the literature. Pediatr Dermatol. 2020;37(1):124-129. https:// doi.org/10.1111/pde.14044. Literature review on DRESS in the pediatric population, covering reports from 1997 to 2019 with focus on presentation and course of DRESS in children. Review of 130 cases showed that presentation, causative drugs, and mortality were largely comparable to adults.

27.• Kardaun SH, Sekula P, Valeyrie-Allanore L, Liss Y, Chu CY, Creamer D, et al. Drug reaction with eosinophilia and systemic symptoms (DRESS): an original multisystem adverse drug reaction. Results from the prospective RegiSCAR study. Br J Dermatol. 2013;169(5):1071-80. https://doi.org/10.1111/bjd.12501. (Systematically performed prospective observational study of 117 DRESS patients by RegiSCAR. Provides significant insight into clinical and biological characteristics, culprit drugs, and temporality of disease onset and resolution.)

28. Kano Y, Hiraharas K, Sakuma K, Shiohara T. Several herpesviruses can reactivate in a severe drug-induced multiorgan reaction in the same sequential order as in graft-versus-host disease. $\mathrm{Br}$ J Dermatol. 2006;155(2):301-6. https://doi.org/10.1111/j.13652133.2006.07238.x.

29. Descamps V, Brunet-Possenti F. Drug reaction with eosinophilia and systemic symptoms or virus reactivation with eosinophilia and systemic symptoms. Pediatr Dermatol. 2016;33(5):562. https://doi.org/10.1111/pde.12931.

30. Herman A, Matthews M, Mairlot M, Nobile L, Fameree L, Jacquet LM, et al. Drug reaction with eosinophilia and systemic symptoms syndrome in a patient with COVID-19. J Eur Acad Dermatol Venereol. 2020;34(12):e768-800. https://doi. org/10.1111/jdv.16838.

31. Shiohara T, Mizukawa Y. Comment on 'Drug reaction with eosinophilia and systemic symptoms syndrome in a patient with COVID-19': involvement of herpesvirus reactivations and adverse drug reactions in diverse cutaneous manifestations and overall disease severity of COVID-19. J Eur Acad Dermatol Venereol. 2021;35(2):e98-100. https://doi.org/10.1111/jdv. 16959.

32. Almeida CA, van Miert P, O'Driscoll K, Zoet YM, Chopra A, Witt C, et al. Virus-specific T-cell clonotypes might contribute to drug hypersensitivity reactions through heterologous immunity. J Allergy Clin Immunol. 2019;144(2):608-11 e4. https://doi.org/ 10.1016/j.jaci.2019.05.009. Proof-of-principal in vitro study supporting $T$ cell cross-reactivity between virus and drug as a potential pathomechanism of DRESS.

33. Lucas A, Lucas M, Strhyn A, Keane NM, McKinnon E, Pavlos $\mathrm{R}$, et al. Abacavir-reactive memory $\mathrm{T}$ cells are present in drug naive individuals. PLoS ONE. 2015;10(2): e0117160. https:// doi.org/10.1371/journal.pone.0117160.

34.• Kim D, Kobayashi T, Voisin B, Jo JH, Sakamoto K, Jin SP, et al. Targeted therapy guided by single-cell transcriptomic analysis in drug-induced hypersensitivity syndrome: a case report. Nat Med. 2020;26(2):236-243. https://doi.org/10.1038/s41591019-0733-7. Excellent example of translational research and personalized medicine. Case study performing single cell analysis and supportive studies on a patient with recalcitrant DRESS demonstrating elevated Janus kinase-signal transducer and activator of transcription (JAK-STAT) pathway. The patient was subsequently successfully treated with tofacitinib.

35. Skowron F, Bensaid B, Balme B, Depaepe L, Kanitakis J, Nosbaum A, et al. Drug reaction with eosinophilia and systemic symptoms (DRESS): clinicopathological study of 45 cases. J Eur Acad Dermatol Venereol. 2015;29(11):2199-205. https://doi.org/10.1111/jdv.13212.

36. Thongsri T, Chularojanamontri L, Pichler WJ. Cardiac involvement in DRESS syndrome. Asian Pac J Allergy Immunol. 2017;35(1):3-10. https://doi.org/10.12932/AP0847.

37. Bourgeois GP, Cafardi JA, Groysman V, Hughey LC. A review of DRESS-associated myocarditis. J Am Acad Dermatol. 2012;66(6):e229-36. https://doi.org/10.1016/j.jaad.2010.11.057.

38. Eshki M, Allanore L, Musette P, Milpied B, Grange A, Guillaume $\mathrm{JC}$, et al. Twelve-year analysis of severe cases of drug reaction with eosinophilia and systemic symptoms: a cause of unpredictable multiorgan failure. Arch Dermatol. 2009;145(1):67-72. https://doi.org/10.1001/archderm.145.1.67.

39. Ozisik L, Tanriover MD, Saka E. Autoimmune limbic encephalitis and syndrome of inappropriate antidiuretic hormone secretion associated with lamotrigine-induced drug rash with eosinophilia and systemic symptoms (DRESS) syndrome. Intern Med. 2016;55(10):1393-6. https://doi.org/10.2169/internalmedicine. 55.6035 .

40.• Cabanas R, Ramirez E, Sendagorta E, Alamar R, Barranco R, Blanca-Lopez N, et al. Spanish guidelines for diagnosis, management, treatment, and prevention of DRESS syndrome. J Investig Allergol Clin Immunol. 2020;30(4):229-53. https:// doi.org/10.18176/jiaci.0480. (Updated evidence-based DRESS guidelines. Provides concise summary of drugs patients could cross-react to based on their culprit drug.)

41. Kano Y, Shiohara T. The variable clinical picture of druginduced hypersensitivity syndrome/drug rash with eosinophilia and systemic symptoms in relation to the eliciting drug. Immunol Allergy Clin North Am. 2009;29(3):481-501. https://doi. org/10.1016/j.iac.2009.04.007.

42. Soria A, Bernier C, Veyrac G, Barbaud A, Puymirat E, Milpied B. Drug reaction with eosinophilia and systemic symptoms may occur within 2 weeks of drug exposure: a retrospective study. J Am Acad Dermatol. 2020;82(3):606-11. https://doi.org/10. 1016/j.jaad.2019.09.036.

43. Milani-Nejad N, Trinidad J, Kaffenberger BH. Viral reactivation in hospitalized patients with drug reaction with eosinophilia and systemic symptoms: a retrospective study from a tertiary medical center in the United States. J Am Acad Dermatol. 2020;83(1):278-9. https://doi.org/10.1016/j.jaad.2020.03.095.

44. Cho YT, Yang CW, Chen YC, Chu CY. Comment on "Viral reactivation in hospitalized DRESS patients: a retrospective study from a tertiary medical center in the United States." J Am Acad Dermatol. 2020;83(3):e209-10. https://doi.org/10.1016/j.jaad. 2020.04.175.

45. Milani-Nejad N, Trinidad J, Kaffenberger BH. Reply to: "Comment on viral reactivation in hospitalized DRESS patients: a retrospective study from a tertiary medical center in the United States." J Am Acad Dermatol. 2020;83(3): e211. https://doi.org/ 10.1016/j.jaad.2020.05.022.

46. Chi MH, Hui RC, Yang CH, Lin JY, Lin YT, Ho HC, et al. Histopathological analysis and clinical correlation of drug reaction with eosinophilia and systemic symptoms (DRESS). Br J Dermatol. 2014;170(4):866-73. https://doi.org/10.1111/bjd.12783.

47. Ortonne N, Valeyrie-Allanore L, Bastuji-Garin S, Wechsler J, de Feraudy S, Duong TA, et al. Histopathology of drug rash with eosinophilia and systemic symptoms syndrome: a morphological and phenotypical study. Br J Dermatol. 2015;173(1):50-8. https://doi.org/10.1111/bjd.13683.

48. Skowron F, Bensaid B, Balme B, Depaepe L, Kanitakis J, Nosbaum A, et al. Comparative histological analysis of druginduced maculopapular exanthema and DRESS. J Eur Acad Dermatol Venereol. 2016;30(12):2085-90. https://doi.org/10. $1111 / j d v .13832$. 
49. Jeong J, Sim DW, Yu JE, Choi YD, Kim SK, Yoon W, et al. Differentiation of angioimmunoblastic T-cell lymphoma from DRESS syndrome. J Allergy Clin Immunol Pract. 2019;7(5):1684-6 e1. https://doi.org/10.1016/j.jaip.2018.11.048.

50. Cardones AR. Drug reaction with eosinophilia and systemic symptoms (DRESS) syndrome. Clin Dermatol. 2020;38(6):70211. https://doi.org/10.1016/j.clindermatol.2020.06.008.

51. Kim DH, Koh YI. Comparison of diagnostic criteria and determination of prognostic factors for drug reaction with eosinophilia and systemic symptoms syndrome. Allergy Asthma Immunol Res. 2014;6(3):216-21. https://doi.org/10.4168/aair. 2014.6.3.216.

52. Isaacs M, Cardones AR, Rahnama-Moghadam S. DRESS syndrome: clinical myths and pearls. Cutis. 2018;102(5):322-6.

53. Bouvresse S, Valeyrie-Allanore L, Ortonne N, Konstantinou MP, Kardaun SH, Bagot M, et al. Toxic epidermal necrolysis, DRESS, AGEP: do overlap cases exist? Orphanet J Rare Dis. 2012;7:72. https://doi.org/10.1186/1750-1172-7-72.

54. Husain Z, Reddy BY, Schwartz RA. DRESS syndrome: Part II. Management and therapeutics. J Am Acad Dermatol. 2013;68(5):709 e1-9; quiz 18-20. https://doi.org/10.1016/j.jaad. 2013.01.032.

55. Suthumchai N, Srinoulprasert $Y$, Thantiworasit P, Rerknimitr $\mathrm{P}$, Tuchinda P, Chularojanamontri L, et al. The measurement of drug-induced interferon gamma-releasing cells and lymphocyte proliferation in severe cutaneous adverse reactions. J Eur Acad Dermatol Venereol. 2018;32(6):992-8. https://doi.org/10.1111/ jdv. 14890 .

56. Trubiano JA, Strautins K, Redwood AJ, Pavlos R, Konvinse KC, Aung AK, et al. The combined utility of ex vivo IFN-gamma release enzyme-linked immunospot assay and in vivo skin testing in patients with antibiotic-associated severe cutaneous adverse reactions. J Allergy Clin Immunol Pract. 2018;6(4):1287-96 e1. https://doi.org/10.1016/j.jaip.2017.09.004.

57. Cabanas R, Calderon O, Ramirez E, Fiandor A, Caballero T, Heredia R, et al. Sensitivity and specificity of the lymphocyte transformation test in drug reaction with eosinophilia and systemic symptoms causality assessment. Clin Exp Allergy. 2018;48(3):325-333. https://doi.org/10.1111/cea. 13076. Assesses and optimizes the sensitivity and specificity of the LTT to specific drugs in DRESS patients to allow for clinical implementation. LTT was particularly useful when testing anticonvulsants, antituberculosis medications, and beta-lactams.

58. Santiago F, Goncalo M, Vieira R, Coelho S, Figueiredo A. Epicutaneous patch testing in drug hypersensitivity syndrome (DRESS). Contact Dermatitis. 2010;62(1):47-53. https://doi. org/10.1111/j.1600-0536.2009.01659.x.

59. Barbaud A, Collet E, Milpied B, Assier H, Staumont D, Avenel-Audran M, et al. A multicentre study to determine the value and safety of drug patch tests for the three main classes of severe cutaneous adverse drug reactions. Br J Dermatol. 2013;168(3):555-62. https://doi.org/10.1111/bjd.12125.

60. Lehloenya RJ, Isaacs T, Nyika T, Dhana A, Knight L, Veenstra $\mathrm{S}$, et al. Early high-dose intravenous corticosteroids rapidly arrest Stevens Johnson syndrome and drug reaction with eosinophilia and systemic symptoms recurrence on drug re-exposure. J Allergy Clin Immunol Pract. 2021;9(1):582-4 e1. https://doi. org/10.1016/j.jaip.2020.08.012.

61. Shiohara T, Kano Y. Drug reaction with eosinophilia and systemic symptoms (DRESS): incidence, pathogenesis and management. Expert Opin Drug Saf. 2017;16(2):139-47. https://doi.org/ 10.1080/14740338.2017.1270940.

62. Natkunarajah J, Goolamali S, Craythorne E, Benton E, Smith $\mathrm{C}$, Morris-Jones R, et al. Ten cases of drug reaction with eosinophilia and systemic symptoms (DRESS) treated with pulsed intravenous methylprednisolone. Eur J Dermatol. 2011;21(3):385-91. https://doi.org/10.1684/ejd.2011.1300.

63. Funck-Brentano E, Duong TA, Bouvresse S, Bagot M, Wolkenstein P, Roujeau JC, et al. Therapeutic management of DRESS: a retrospective study of 38 cases. J Am Acad Dermatol. 2015;72(2):24652. https://doi.org/10.1016/j.jaad.2014.10.032.

64. Morikawa D, Hiraoka E, Obunai K, Norisue Y. Myocarditis associated with drug reaction with eosinophilia and systemic symptoms (DRESS) syndrome: a case report and review of the literature. Am J Case Rep. 2018;19:978-84. https://doi.org/10. 12659/AJCR.909569.

65.• Tohyama M, Hashimoto K, Oda F, Namba C, Sayama $\mathrm{K}$. Influence of corticosteroid therapy on viral reactivation in drug-induced hypersensitivity syndrome/drug reaction with eosinophilia and systemic symptoms. J Dermatol. 2020;47(5):476-482. https://doi.org/10.1111/1346-8138. 15294. Study showing that high-dose corticosteroid treatment initiated within 1 week after disease onset interfered with HHV-6 reactivation with remarkable suppression of serum sIL-2R levels.

66. Nguyen E, Yanes D, Imadojemu S, Kroshinsky D. Evaluation of cyclosporine for the treatment of DRESS syndrome. JAMA Dermatol. 2020;156(6):704-6. https://doi.org/10.1001/jamadermatol. 2020.0048 .

67. Joly P, Janela B, Tetart F, Rogez S, Picard D, D'Incan M, et al. Poor benefit/risk balance of intravenous immunoglobulins in DRESS. Arch Dermatol. 2012;148(4):543-4. https://doi.org/ 10.1001/archderm.148.4.dlt120002-c.

68. Damsky WE, Vesely MD, Lee AI, Choi J, Meyer AC, Chen $\mathrm{M}$, et al. Drug-induced hypersensitivity syndrome with myocardial involvement treated with tofacitinib. JAAD Case Rep. 2019;5(12):1018-26. https://doi.org/10.1016/j.jdcr.2019.07.004.

69. Chen YC, Chang CY, Cho YT, Chiu HC, Chu CY. Long-term sequelae of drug reaction with eosinophilia and systemic symptoms: a retrospective cohort study from Taiwan. J Am Acad Dermatol. 2013;68(3):459-65. https://doi.org/10.1016/j.jaad.2012. 08.009 .

70. Kano Y, Tohyama M, Aihara M, Matsukura S, Watanabe H, Sueki $\mathrm{H}$, et al. Sequelae in 145 patients with drug-induced hypersensitivity syndrome/drug reaction with eosinophilia and systemic symptoms: survey conducted by the Asian Research Committee on Severe Cutaneous Adverse Reactions (ASCAR). J Dermatol. 2015;42(3):276-82. https://doi.org/10.1111/13468138.12770.

71. Lew TT, Creamer D, Mackenzie J, Walsh SA. Post-traumatic stress disorder following drug reaction with eosinophilia and systemic symptoms. Br J Dermatol. 2015;172(3):836-7. https:// doi.org/10.1111/bjd.13375.

72. Mounzer K, Hsu R, Fusco JS, Brunet L, Henegar CE, Vannappagari $\mathrm{V}$, et al. HLA-B*57:01 screening and hypersensitivity reaction to abacavir between 1999 and 2016 in the OPERA((R)) observational database: a cohort study. AIDS Res Ther. 2019;16(1):1. https://doi. org/10.1186/s12981-019-0217-3.

73. Quiros-Roldan E, Gardini G, Properzi M, Ferraresi A, Carella G, Marchi A, et al. Abacavir adverse reactions related with HLAB*57: 01 haplotype in a large cohort of patients infected with HIV. Pharmacogenet Genomics. 2020;30(8):167-74. https://doi. org/10.1097/FPC.0000000000000409.

74. Hung SI, Chung WH, Liou LB, Chu CC, Lin M, Huang HP, et al. HLA-B*5801 allele as a genetic marker for severe cutaneous adverse reactions caused by allopurinol. Proc Natl Acad Sci U S A. 2005;102(11):4134-9. https://doi.org/10.1073/pnas. 0409500102.

75. Kang HR, Jee YK, Kim YS, Lee CH, Jung JW, Kim SH, et al. Positive and negative associations of HLA class I alleles with allopurinol-induced SCARs in Koreans. Pharmacogenet 
Genomics. 2011;21(5):303-7. https://doi.org/10.1097/FPC. 0b013e32834282b8.

76. Sukasem C, Jantararoungtong T, Kuntawong P, Puangpetch A, Koomdee N, Satapornpong P, et al. HLA-B (*) 58:01 for allopurinol-induced cutaneous adverse drug reactions: implication for clinical interpretation in Thailand. Front Pharmacol. 2016;7:186. https://doi.org/10.3389/fphar.2016.00186.

77. Genin E, Chen DP, Hung SI, Sekula P, Schumacher M, Chang PY, et al. HLA-A*31:01 and different types of carbamazepineinduced severe cutaneous adverse reactions: an international study and meta-analysis. Pharmacogenomics J. 2014;14(3):2818. https://doi.org/10.1038/tpj.2013.40.

78. McCormack M, Alfirevic A, Bourgeois S, Farrell JJ, Kasperaviciute D, Carrington M, et al. HLA-A*3101 and carbamazepine-induced hypersensitivity reactions in Europeans. N Engl J Med. 2011;364(12):1134-43. https://doi.org/10.1056/ NEJMoa1013297.

79. Niihara H, Kakamu T, Fujita Y, Kaneko S, Morita E. HLA-A31 strongly associates with carbamazepine-induced adverse drug reactions but not with carbamazepine-induced lymphocyte proliferation in a Japanese population. J Dermatol. 2012;39(7):594601. https://doi.org/10.1111/j.1346-8138.2011.01457.x.

80. Ozeki T, Mushiroda T, Yowang A, Takahashi A, Kubo M, Shirakata Y, et al. Genome-wide association study identifies HLA-A*3101 allele as a genetic risk factor for carbamazepineinduced cutaneous adverse drug reactions in Japanese population. Hum Mol Genet. 2011;20(5):1034-41. https://doi.org/10. 1093/hmg/ddq537.

81. Zhang FR, Liu H, Irwanto A, Fu XA, Li Y, Yu GQ, et al. HLA-B*13:01 and the dapsone hypersensitivity syndrome. N Engl J Med. 2013;369(17):1620-8. https://doi.org/10.1056/ NEJMoa1213096.

82. Tempark T, Satapornpong P, Rerknimitr P, Nakkam N, Saksit N, Wattanakrai P, et al. Dapsone-induced severe cutaneous adverse drug reactions are strongly linked with HLA-B*13: 01 allele in the Thai population. Pharmacogenet Genomics. 2017;27(12):429-37. https://doi.org/10.1097/ FPC.0000000000000306.

83. Chen WT, Wang CW, Lu CW, Chen CB, Lee HE, Hung SI, et al. The function of HLA-B*13:01 involved in the pathomechanism of dapsone-induced severe cutaneous adverse reactions. J Invest Dermatol. 2018;138(7):1546-54. https://doi.org/10.1016/j.jid. 2018.02.004

84. Satapornpong P, Pratoomwun J, Rerknimitr P, Klaewsongkram J, Nakkam N, Rungrotmongkol T, et al. HLA-B*13:01 is a predictive marker of dapsone-induced severe cutaneous adverse reactions in Thai patients. Front Immunol. 2021;12: 661135. https:// doi.org/10.3389/fimmu.2021.661135.

85. Manuyakorn W, Likkasittipan P, Wattanapokayakit S, Suvichapanich S, Inunchot W, Wichukchinda N, et al. Association of HLA genotypes with phenytoin induced severe cutaneous adverse drug reactions in Thai children. Epilepsy Res. 2020;162: 106321. https://doi.org/10.1016/j.eplepsyres.2020.106321.

86. Thomas M, Hopkins C, Duffy E, Lee D, Loulergue P, Ripamonti $\mathrm{D}$, et al. Association of the HLA-B*53:01 allele with drug reaction with eosinophilia and systemic symptoms (DRESS) syndrome during treatment of HIV infection with raltegravir. Clin Infect Dis. 2017;64(9):1198-203. https://doi.org/10.1093/cid/ cix096.

87. Konvinse KC, Trubiano JA, Pavlos R, James I, Shaffer CM, Bejan CA, et al. HLA-A*32:01 is strongly associated with vancomycin-induced drug reaction with eosinophilia and systemic symptoms. J Allergy Clin Immunol. 2019;144(1):183-92. https://doi.org/10.1016/j.jaci.2019.01.045.

88. Cacoub P, Musette P, Descamps V, Meyer O, Speirs C, Finzi L, et al. The DRESS syndrome: a literature review. Am J Med. 2011;124(7):588-97. https://doi.org/10.1016/j.amjmed.2011.01. 017.

89. Cho YT, Yang CW, Chu CY. Drug reaction with eosinophilia and systemic symptoms (DRESS): an interplay among drugs, viruses, and immune system. Int J Mol Sci. 2017;18(6). https:// doi.org/10.3390/ijms18061243.

90. Di Palma-Grisi JC, Vijayagopal K, Muslimani MA. Case reports of DRESS syndrome and symptoms consistent with DRESS syndrome following treatment with recently marketed monoclonal antibodies. Autoimmune Dis. 2019;2019:7595706. https://doi. org/10.1155/2019/7595706.

Publisher's Note Springer Nature remains neutral with regard to jurisdictional claims in published maps and institutional affiliations. 